\title{
100ste BESTUURSVERGADERING
}

VAN 15 SEPTEMmber 1866.

\section{nearer}

Tegenwoordig de heeren Jhr. Gevers Deynoot (Voorzitter), Millard, Godon, Bachiene, Egter van Wissekerke, Francis, van der Gon Netscher, prof. Hoffmann, dr. Niemann, Obreen en de Adjunct-secretaris. De heer Robidé van der Aa tengevolge van eene buitenlandsche reis afwezig.

De notulen van het verhandelde in de vorige vergadering worden gelezen en goedgekeurd.

De Voorzitter bericht de ontvangst van:

I. De navolgende boekwerken:

Annuel report of the board of regents of the Smithsonian institution for the year 1864 .

Journal of the Asiatic society of Bengal, part. $\mathrm{l}$ en $\Pi \mathrm{n}^{0} .1$, 1866.

Proceedings of the Asiatic society of Bengal, no. I-XI for 1865 with title, index and appendix, no. I-III for 1866.

Proceedings of the Royal geographical society.

Erster Jahresbericht des Vereins für Erdkunde zu Dresden.

Zeitschrift der Deutschen morgenländischen Gesellschaft, 20e dl. afl. $1-3$.

Abhandlungen für die Kunde des Morgenlandes, 4e dl., no. 2-4.

Bulletin de la société de géographie, afl. Juli en Aug. 1866.

Tijdschrift voor Ned. Indië, afl. Aug. en Sept. 1866.

Tijdschrift uitgegeven door de Ned. maatschappij ter bevordering van nijverheid, $3 \mathrm{e}$ reeks, $7 \mathrm{e}$ deel, $7 \mathrm{e}$ en $8 \mathrm{e}$ stuk.

Verslagen en mededeelingen der Koninklijke academie van wetenschappen, afd. Letterkunde, $10 \mathrm{e}$ dl., $1^{\mathrm{e}}$ en $2 \mathrm{e}$ stuk, afd. Natuurkunde, 1e deel 3e stuk. 
Catalogus der boekerij van de Koninklijke academie van wetenschappen, te Amsterdam, 2e deel 1e stuk.

Revue maritime et coloniale, afl. Augustus 1866.

Catalogue d'une précieuse collection de livres relatifs à l'etude de la linguistique et des langues et litterature orientales, qui se trouvent chez F. A. Brockhaus.

Van den heer Jhr. Cornets de Groot van Kraaijenburg, een exemplaar der: Grammaire Javanaise van P. Favre.

Van dr. Favrot, een exemplaar van zijn geschrift: Mahomet, les sciences chez les Arabes.

Van dr. H. N. v. d. Tuuk, een exemplaar van: Kurzer Abriss einer Batta'schen Formenlehre im Toba-dialecte, in het Duitsch vertaald door A. Schreiber.

Van dr. J. A. van Dissel te Samarang, een exemplaar van : Uitnemende en zeer wonderlicke zee- en landtreise van d'Heer Ludowick di Barthema, uitgegeven in 1654 .

Van het Ministerie van kolonien: Souvenir du Japon, afl. 9 en 10.

Verslag van den handel, de scheepvaart en de inkomende en nitgaande rechten op Java en Madura over 1864.

Jaarboekje Celebes 1866.

De opstand van Amir.

Een woord over de invoering van het metriek stelsel van maten en gewigten in N. I. door G. Warnar.

Verzameling der merkwaardigste vonnissen gewezen door de krijgsraden te velde in de Z. en O. afd. van Borneo, gedurende $1859-1864$.

II. Missives van de heeren dr. Kern, W. Wijt en Jhr. Mr. J. K. W. Quarles van Ufford kennisgevende van de aanneming van het hun opgedragen lidmaatschap.

III. Eene missive van den heer Reinhold Rost te Londen, houdende dankbetuiging voor zijne benoeming tot buitenlandsch lid van het genootschap.

IV. Eene missive van La commission des monuments et documents historiques et des bâtiments civils, departement de la Gironde, voorstellende ruiling van werken. Het Bestuur, van oordeel dat het belang van het Genootschap medebrengt zijne betrekkingen met buitenlandsche maatschappijen en vereenigingen 
zooveel mogelijk uit te breiden, vereenigt zich met het gedane voorstel en besluit de genoemde instelling het Tijdschrift en de werken van het Instituut geregeld te doen toezenden.

V. Eene missive van het lid des Instituuts, den heer E. W. A. Ludeking te Makassar, berichtende de spoedige afzending van een opstel, getiteld: "Schets der residentie Amboina ", om door het Instituut, wanneer het Bestuur meent dat daartoe termen zijn, als een afzonderlijk werk te worden uitgegeven. Wordt besloten de ontvangst van de toegezegde bijdrage af te wachten.

VI. Eene missive van den heer J. van Leeuwen te Amsterdam, 10. toezendende twee lijstjes van drukfouten in? de beide opstellen van den heer Klinkert, opgenomen in de Bijdragen $3 \mathrm{e}$ reeks, le deel, le stuk, blz. 37-112;

2. namens den heer Klinkert ter opneming in de Bijdragen anbiedende een uittreksel uit een Maleische hikajat.

Hieromtrent wordt besloten: de lijstjes van drukfouten op te nemen in het eerst verschijnend nommer der Bijdragen en het ter publiceering aangeboden opstel in handen te stellen van den heer dr. Niemann om het Bestuur omtrent de wenschelijkheid tot opneming daarvan in de Bijdragen te adviseeren.

Naar aanleiding van eene missive van den heer Frederik Muller te Amsterdam omtrent de uitgave van het werk van den heer van der Chijs: Neêrlands streven tot openstelling van Japan voor den wereldhandel, deelt de heer Millard mede dat aan het werk is toegevoegd eene voorrede van den heer Keyser, als secretaris van het Instituut, gedagteekend Juni 1864. Daar de vergadering meent dat het Instituut thans moeilijk een werk kan uitgeven dat eene voorrede bevat, die reeds twee jaren geleden geschreven werd, te meer omdat na dien tijd in onze verhouding tegenover Japan het een en ander gebeurd is dat vermelding zou verdienen, wordt den heer Millard opgedragen eene nieuwe voorrede aan het werk toe te voegen waarin het gebeurde van de laatste jaren met een woord wordt aangestipt.

De Voorzitter deelt mede dat de heeren Robidé van der Aa, van der Gon Netscher en Obreen gunstig hebben gerapporteerd omtrent de uitgave van het werk des heeren von Rosenberg (zie 
de notulen der vorige vergadering) en dat door hen wordt voorgesteld het reisverhaal uit te geven als een afzonderlijk werk. De vergadering vereenigt zich met dit voorstel en besluit verder aan het werk toe te voegen eenige afbeeldingen van bewoners der Aroe-Kei-eilanden, die tot dit doel door den heer van der Gon Netscher worden afgestaan.

De Voorzitter brengt vervolgens rapport uit omtrent de publiceering van het verslag des heeren J. J. van Sevenhoven over Billiton. Naar het oordeel van den Voorzitter is het rapport zeer oppervlakkig te noemen, zoodat hij in overweging geeft nog niet tot de opneming in de Bijdragen te besluiten. Daar de heer Francis verklaart dat hij gelijktijdig met den heer van Sevenhoven op Billiton is geweest, wordt hij uitgenoodigd ook zijn oordeel over het rapport te doen kennen.

De heer Niemann deelt mede dat hem de Pelgrimsreis van Abdullah naar Mecca (zie de notulen der vorige bestuursvergadering) zeer geschikt voorkomt ter plaatsing in de Bijdragen, behoudens eenige aanteekeningen waar vergissingen of omissien voorkomen. De vergadering besluit daarop het opstel, voorzien van de vereischte aanteekeningen, den secretaris ter hand te stellen ter opneming in de Bijdragen.

Naar aanleiding van de door den heer de Grijss aangeboden hollandsche vertaling der chineesche wetboeken bericht de heer Hoffmann dat in 1810 te Londen door Sir G. Th. Staunton is uitgegeven: Ta-tsing-leu-lee; being the fundamental laws and a selection from the supplementary statutes of the penal code of China; translated from the Chinese and accompanied with an appendix consisting of authentic documents and a few occasional notes. Van dit werk werd in 1812 door F. Benouard de St. Croix eene fransche vertaling bezorgd. De heer de Grijs heeft, omdat zoowel de engelsche als de fransche vertaling moeilijk te verkrijgen is, de chineesche wetboeken op nieuw en thans in het hollandsch vertaald. Die arbeid is, naar het oordeel des heeren Hoffmann, wel waard door het Instituut als afzonderlijk werk te worden uitgegeven. Sommige leden kunnen evenwel het nut van de hollandsche vertaling niet inzien, omdat het hier de strafwetboeken geldt, die niet speciaal voor ons van nut kunnen worden geacht, en zouden daarom aan eene overzetting 
-in het engelsch de voorkeur gegeven. Nu evenwel eene engelsche vertaling reeds vroeger is uitgegeven, achten zij de hollandsche overzetting vrij overbodig. De beslissing van deze zaak wordt tot eene volgende bijeenkomst aangehouden.

De Voorzitter stelt aan de orde de bespreking van het denkbeeld van den heer Obreen dat het geacht zou kunnen worden tot de taak van het Instituut te behooren, om te trachten eenige gelijkvormigheid tot stand te brengen in de spelling van indische plaatsnamen. Op nieuw worden door den heer Niemann, die daarin door den heer Millard wordt ondersteund, bezwaren tegen de uitvoerbaarheid van dit denkbeeld geopperd, waarop de heer Obreen verklaart zijn voorstel in te trekken.

Niets verder aan de orde zijnde, sluit de Voorzitter de vergadering.

\section{1ste BESTUURSVERGADER I NG.}

\section{VAN 17 NOVEMBER 1866.}

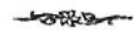

Tegenwoordig de heeren Jhr. Gevers Deynoot (Voorzitter), dr. Bleeker, Obreen, v. d. Gon Netscher, Francis, dr. Niemann, Robidé van der Aa, Egter van Wissekerke, Bachiene, prof. Hoffinann en de Adjunctsecretaris. Afwezig de heeren Millard en Godon; eerstgenoeinde door ongesteldheid, de tweede omdat hij zich uit de stad heeft moeten begeven.

De notulen vau het verhandelde in de vorige vergadering worden gelezen en goedgekeurd.

De Voorzitter deelt mede dat is ingekomen:

I. De navolgende boekwerken:

Bulletin de la société de géographie, afl. September 1866.

Verhandelingen van het Koninklijk instituut voor ingenieurs $1865 / 66$, afl. 1 en 2. 